\title{
Oculocerebral hypopigmentation syndrome, Cross type
}

INSERM

\section{Source}

INSERM. (1999). Orphanet: an online rare disease and orphan drug data base. Oculocerebral hypopigmentation syndrome, Cross type. ORPHA:2719

Oculocerebral hypopigmentation syndrome, Cross type is a rare congenital syndrome characterized by cutaneous and ocular hypopigmentation, various ocular anomalies (e.g. corneal and lens opacity, spastic ectropium, and/or nystagmus), growth deficiency, intellectual deficit and other progressive neurologic anomalies such as spastic tetraplegia, hyperreflexia, and/or athetoid movements. The clinical picture varies among patients and may also include other anomalies such as urinary tract abnormalities, Dandy-Walker malformations, and/or bilateral inguinal hernia. 